\title{
Design and Implementation of Hubei Tourism Meteorological Service System Based on GIS
}

\author{
Lu Jing, Luo Xuerong \\ Hubei Meteorological Service Center, Wuhan City,Hubei Province, China \\ jing009@163.com
}

Keywords: Tourism Meteorology; Service system; GIS; Design.

Abstract. In recent years, with the rapid development of the tourism industry and the increasing demand of GIS technology, in order to enhance the provincial tourism meteorological services capabilities, GIS technology has been widely used in the meteorological field. Facing the application demand of tourism in Hubei Province meteorological services, this paper aimed at the present situation of tourism in Hubei province meteorological service, analysis the framework and principle of Hubei province tourism meteorological service system based on GIS.

\section{Introduction}

In recent years, with the rapid development of tourism and wider use of geographic information systems, to enhance the competitiveness of the city through tourism has become a powerful factor in increasing the city's image. Hubei tourism meteorological service system based on GIS is through the integration of the province's meteorological information, to transfer the weather conditions in various regions to visitors and provide guidance and advice for the passengers' travel. Therefore, the study on Hubei tourism meteorological service system based on GIS is very necessary.

\section{System Functional Requirements Analysis}

Construction of travel weather forecasting service integrated system and public service website includes two aspects: one is comprehensive travel weather forecast service system; the other is travel weather public service website. The functional structure of the whole system is shown as Fig. 1:

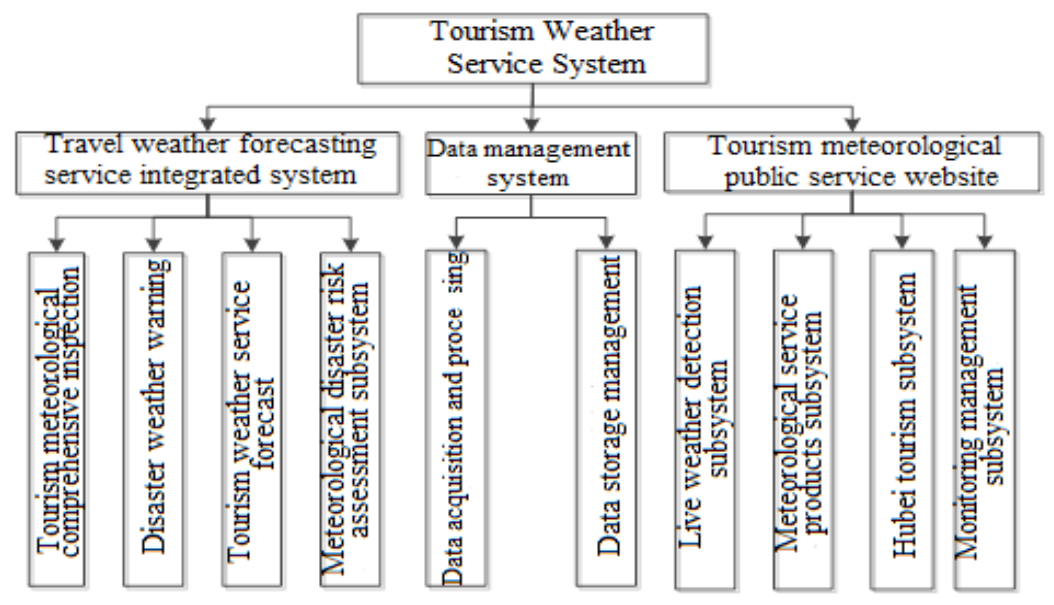

Figure 1. Overall functional structure

The travel weather forecasting service integrated system uses weather diagnostic methods, statistical forecasting methods, numerical prediction, similar forecast, conventional weather forecasting, prediction model and other methods, to study live alarm products, disaster weather warning products, travel weather service forecast products and so on, and carry out assessment test on the forecast results. 
Tourism meteorological public service website is based on weather station, to realize the meteorological monitoring, weather warning and weather forecast of tourist attractions based on GIS, and build a secure network environment. We hope to release tourism meteorological public service products in the form of the Internet, so that the public can grasp resort weather disaster warning information via the website, which is convenient for tourism management department, tourism companies and tourists to arrange and plan for all kinds of tourism. There is no doubt that the system can effectively promote the wisdom tourism construction and tourist information technology development of Hubei province.

\section{System Overall Design}

Hubei travel weather forecasting service integrated system and public service website are composed of the application software system and its supporting environment. The application software system of Hubei travel weather forecasting service integrated system and public service website includes data layer, support layer, application layer and presentation layer. The supporting environment of Hubei travel weather forecasting service integrated system and public service website includes basic hardware layer and basic software layer, and takes the standard system, security system and maintenance management system based on business, technology, management as the support and safeguard on the whole structure.

The data contained in the system include real-time meteorological information, geographic information, early warning and forecasting products and travel information, and provides data integration interface.

Support layer includes data platform, data integration interface, etc.

Application layer includes travel warning forecasting model libraries, data platform, GIS application libraries.

Presentation layer is mainly tour weather live monitoring, travel weather service website, travel weather warning and forecast products, tourism meteorological management and monitoring, and meanwhile provides interface integration interface.

The overall design of the system of nature is inseparable from its associated frame structure, which can be roughly divided into the following frames: application-related architecture, corresponding data frame, basic technical infrastructure and interface design.

1) Application-related architecture: the so-called application architecture is referring to where the system is to be used, clearly reflecting the meteorological forecast service and the contents of the service network. Through this connect Hubei weather and environment, thus we can timely feedback the related weather and environment information. The application includes forecast software of weather bureau, service software of weather bureau and common building service platform. These platforms can report the weather conditions of the day in real time, and the information would give visitors a warning, to make their travel better.

2) Data frame: certainly, system design requires the support of a lot of data. Data frame is to transform the analog information into digital information, and then with computer, combine the knowledge of statistics to get weather information and feedback to the tourists, which is the core of the application architecture. The data frame of this system can be divided into three parts: first is the meaning of the data and its classification; second are some characteristic and attribute of meteorological data; third is structural property and main component of data. Weather system architecture data distribution is shown in Fig. 2: 


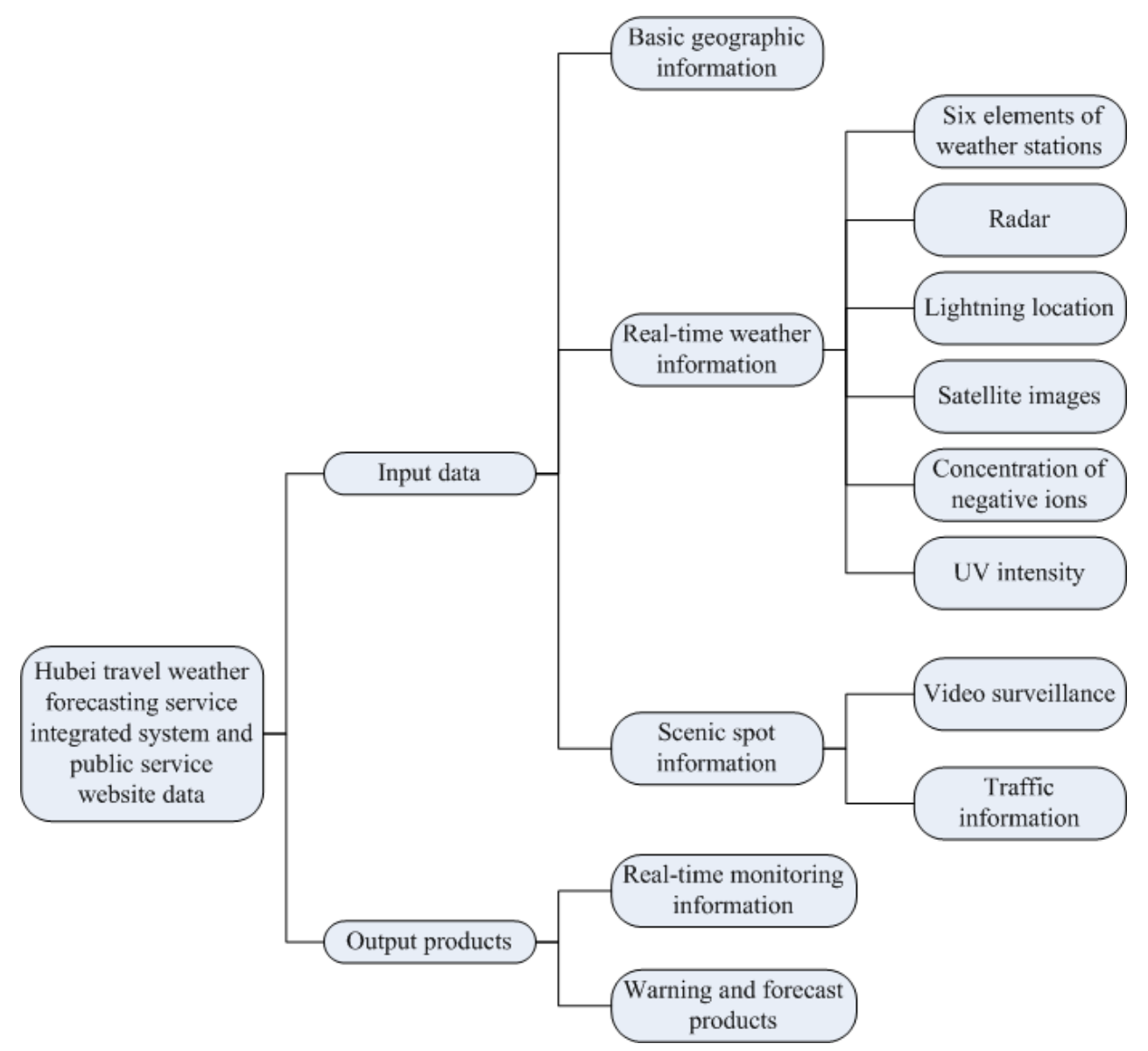

Figure 2. Weather system architecture data distribution

3) Basic technical infrastructure: technology is the core of the whole system design, and single technology is unable to achieve the design of the system, so it must adopt integrated technologies and multiple modules to complete the complex information service function of the whole system, and meanwhile improve the information service ability of the system.

4) Interface design: interface includes external and user interface. The obtained weather data need to be processed with computer. Thus, data transmission to the computer and other related processing tools have become the key, so interface design is also very important.

\section{System Implementation}

System implementation is a very important task. Only the normal operation of the system can ensure the implementation of weather forecasts. Implementation of system includes the following aspects.

Tourism Meteorological Data Center Construction. Conduct tourism meteorological data center construction in Hubei provincial meteorological information and technical support center, to achieve the massive storage of province's tourism meteorological data, tourism meteorological information processing, and internal and external sharing of tourism meteorology real-time information. For the obtained travel meteorological information and external sector share data, system can launch real-time processing, automatically storage into the database, and generate log files. Meanwhile, for province tourism station data, carry out real-time monitoring on integrity and timeliness of tourism station data, in accordance with the requirements of the China Meteorological Administration.

Client and Web Interface Design. As same as Windows OS, information system often has a specific interface, so does Hubei provincial tourism meteorological service system. In interface design, we should combine the use and habit of the common software, allowing users to quickly find the corresponding functions and complete the appropriate actions. In the system interface 
design process, it is generally composed of three main parts: the toolbar, the main display interface, and the functions of the buttons. Therefore, implementation of these three parts is to implement the system interface.

Travel Weather Integrated Forecasting System. To realize prediction and analysis platform for human computer interaction (HCI) based on GIS will provide support for display, analysis and editing functions of integrated meteorological data. Integrated meteorological data includes weather monitoring data, satellite remote sensing monitoring data, radar monitoring data, numerical model prediction and weather forecast products, etc. All the information is the basis of the weather forecast and analysis. The HCI prediction and analysis platform is able to display these meteorological observations by calling the unified meteorological data engine on the GIS map. In addition to providing all kinds of monitoring data related to weather and weather services, the platform can also provide commonly used drawing, editing, modifying and adding weather symbols, as well as their corresponding editing and correction ability, further strengthening the accuracy of forecasting products.

Travel Weather Severe Weather Warning Platform. Analyze resorts severe weather warning indicator threshold, combined with real-time monitoring data, and based on the analysis of Weather situation and NCEP, T639, WRF and other numerical forecast products, relying on MYNOS, SWAN and other short-term disaster prediction system, to achieve timely and automatic alarm of disastrous weather like heavy rain (snow), high winds, low visibility, high temperature, low temperature, thunder and lightning, etc. For tourism traffic safety needs, combine meteorological monitoring information and highway traffic information, to conduct analysis of meteorological factors and highway safety, and then provide the service of travel weather severe weather warning.

In addition, this platform is also able to analyze the adaptability of climate conditions in scenic spots, and probability of extreme climate events, etc. It establishes the meteorological disaster risk assessment business of scenic spots, to provide the countermeasures and suggestions for the development of tourism resources, and how to adapt to the weather and climate conditions, so that reduce or avoid the impact of weather disasters.

\section{Conclusion}

In this paper, we study and design the Hubei provincial tourism meteorological service system based GIS, which can effectively help visitors acquire the local weather information, environmental geology information and other information, so that provide the scientific guidance to the tourists to take corresponding measures in their tourism, to avoid unnecessary troubles and even disasters. Such information system based on GIS is very necessary, and meanwhile the Hubei provincial tourism meteorological service system based GIS effectively improve the level of tourism meteorological service in Hubei province, and is of great significance to attract more tourists to Hubei province.

\section{References}

[1] Mica Jovanovic,Jovan Jovanovic. Implementation of a quality management system in meteorological practice in Serbia. Accreditation and Quality Assurance,2008,131.

[2] Sandra C.B. Barreira. The effects of the parameterization of physical processes in the Argentine Naval Meteorological service five-level model. Atmospheric Research,1996,431.

[3] Y. Khan,A.A. Khan,F.N. Budiman,A. Beroual,N.H. Malik,A.A. Al-Arainy. Partial discharge pattern analysis using support vector machine to estimate size and position of metallic particle adhering to spacer in GIS. Electric Power Systems Research,2014,116.

[4] S.Y. Yang, L.I. Ling. Research Development of Tourism Meteorology and Climate Studies. Journal of Guilin Institute of Tourism, 2007. 
[5] Dong X S. The Design and Implementation of Meteorology Inquiry Service System Based on GIS. Microcomputer Information, 2010, 26(7):146-60.

[6] L.I. Li, Z. Yuan, R. Liu. Implementation for Distributed Service System of Aeronautical Meteorology Information. Computer Engineering, 2005. 